\title{
Effective Marketing Strategies to Promote Engagement with Online Mathematics Learning Support
}

Aoife Guerin, Mathematics Learning Centre, Centre for Teaching and Learning, University of Limerick, Co. Limerick, Ireland. Email: Aoife.Guerin@ul.ie.

Richard Walsh, Mathematics Learning Centre, Centre for Teaching and Learning, University of Limerick, Co. Limerick, Ireland. Email: Richard.Walsh@ul.ie.

\begin{abstract}
In this paper we report on the effects of a different marketing strategy on promoting engagement with the online Mathematics Learning Support (MLS) service (mostly screencasts) compared to our traditional advertising approach which was solely to send generic emails to students advertising the online services. The findings show that this new marketing strategy was far more effective than traditional methods of advertising in getting students to engage with the online service. This paper describes the approach taken and compares the engagement with the online services offered by the Mathematics Learning Centre (MLC) before and after utilising the new marketing strategy, the increased engagement from the trial group with the online services compared to the other groups, and the knock-on effects.
\end{abstract}

Keywords: Mathematics Learning Support, support services, online support, examination revision courses.

\section{Introduction and Background}

Mathematics Learning Support (MLS) has become a common service offered to students in most higher education institutions in Ireland and the UK. The establishment of Mathematics Learning Support was in response to the declining mathematical standards of students entering higher education, commonly referred to as the 'mathematics problem' (Symonds, Lawson and Robinson, 2008), which has remained present to the current day. Research has shown that students who used MLS services once were 1.63 times more likely to pass their examinations compared to students who did not attend at all, while students who attended on 15 occasions or more were 14 times more likely to pass (Jacob and Ní Fhloinn, 2018). The necessity of MLS is evident from the authors' own service, where 38,644 student visits have been made to the Mathematics Learning Centre (MLC) over the past 5 academic years. This number does not include students' accessing of online resources that the MLC also provides. However, the popularity of the authors' MLC does not come without its issues. In the past number of years there has been a decline in the number of tutors that have been available to the authors' MLC. This decline is primarily due to restrictions placed on postgraduate students by their funding sources on the number of hours they are permitted to teach per semester/year. The MLC had 17 hourly paid tutors in 2010 compared to 6 that it currently employs. To combat this, the MLC received an extra contract in the past 2 academic years in addition to the manager, both of whom now teach up to 40 hours per week between them. It is envisaged that if students engaged with online resources before visiting the MLC physically then the tutors would be under less pressure during their sessions, some of which can consist of 30 students looking for 1-to-1 help from the 2 tutors per session.

There is increasing awareness and concern over the amount of notifications that students in higher education are receiving regarding the services that are available to them (from sports clubs, support services etc.). In response to the growth in the volume of emails that students need to read through, they may choose to ignore or not read some emails fully (Sappleton and Lourenço, 2016). The 
authors, in their work in MLS, feared that students who need help in mathematics may not avail themselves of MLS due to them being unaware of what the MLC provides and how to access this service. Part of a programme at the university (where this research took place) which assists new students with various aspects of student life, focuses on raising students' awareness of the learning support services that are available to them. However with the range and depth of services offered by the MLC, it has proven very difficult to attract students to the correct resources/use of resources. Many students forget about the online support offered by the MLC and end up physically visiting the centre around examination time. This puts tutors under immense pressure to keep up with the volume of student traffic.

Approximately 22\%, 21\% and 18\% of students use Khan Academy, YouTube, and Wolfram Alpha respectively to try to gain support with their mathematics studies. However student feedback on online resources reveals their desire to have videos/online support specifically tailored to the material that they are actually studying (Ní Shé et al., 2017). Empirically the researchers, through their combined 13 years experience of working in MLS, have observed many students who would benefit from online help before visiting the MLC. However it is apparent that students are not armed with the tools (e.g. they do not have a sufficient mastery of the mathematical terminology required) to search accurately for the resources that they need. Creating videos for particular modules allows lecturers/learning support staff to tailor the videos to the students' needs, even in the terminology that would be more reflective of their lecture notes.

The researchers sought to investigate the impact of an 'attractive' advertising campaign on students' engagement with our online support videos. A module (first year service mathematics module taken by science students, referred to hereafter as the 'trial group') with a historically high number of users of the MLC drop-in centre was used to investigate this. The authors compare these users' engagement with the MLC's online resources to the engagement of other groups who received the same advertising (generic email) as in previous years. The generic email advertised the online resources as mainly videos that cover concepts associated with the student's mathematics module which may be a useful revision tool. A comparison is also made between the trial group's physical attendances at MLC services in the current semester and their physical attendances in previous years where the new 'attractive' videos were not available to them. This comparison looks at the physical attendances in the weeks before and after the date at which the 'attractive' videos were made available.

\section{Methods}

In the semester when this study was completed (Autumn 2018) the MLC serviced 8 first semester mathematics modules on our online service. To avail themselves of this service a student needed to visit our website, click on the module that they wanted the online resources for, and join our Sulis page for their module (Sulis is the university's learning management system, used by lecturers as a way of communicating with their students and sharing resources). The MLC developed its own Sulis pages for certain modules. Each module has its own unique Sulis page for students to join so that data (e.g. the number of visits) is identifiable per module. The modules are described in table 1. There is a similar amount of video support available online on each of the Sulis pages for these 8 modules.

This study investigated the effectiveness of an attractive marketing strategy for the online resources for the 'trial group'. It was planned to trial this strategy with two modules (the second being a first year engineering module) however the second lecturer decided not to participate as he did not want students receiving solutions to past papers. The marketing strategy comprised of completing a past midterm examination paper for the trial group's module over a series of 11 short videos ( 45 minutes 
in total - see figure 1 for example of a screenshot). These videos were created on a tablet computer using the app 'Educreations' which allows the user to write on a 'whiteboard' with a stylus while recording audio simultaneously. Students in the trial group received the same generic advertisement email as their peers in the modules that the MLC have online resources for (listed in table 1) up until 16 days before their midterm examination, from which point the trial group received a different email advertising the online midterm revision course available to them (the email specified that these new videos would talk them through the 2016 midterm examination paper), while the students in the other seven modules continued to receive the original generic email. Students from these eight modules often frequent the MLC with past papers and tutors remark that they teach the same problem multiple times, even in a single session. After adding the online midterm revision course, the number of videos available to students of the trial group was slightly higher than the number of videos available to the students of the other seven modules.

The motivation for using this attractive marketing strategy was the expectation that this would lessen the pressure on tutors in the MLC drop-in sessions by potentially avoiding repetitively teaching the same problems during the weeks leading up to the midterm examination, and therefore avoid rushing with attendees during the sessions.

Table 1. Description of Modules and the number of students in each.

\begin{tabular}{|c|l|c|}
\hline Module & \multicolumn{1}{|c|}{ Description } & \multicolumn{1}{|c|}{$\begin{array}{c}\text { Total Number of } \\
\text { Students }\end{array}$} \\
\hline $\begin{array}{c}\text { Trial } \\
\text { Group }\end{array}$ & $\begin{array}{l}\text { First year science mathematics. Focus on trigonometry, vectors, } \\
\text { matrices, functions and differential calculus. }\end{array}$ & 366 \\
\hline 1 & $\begin{array}{l}\text { Foundation mathematics for mature students pursuing an access } \\
\text { foundation year (in humanities/business/science), following which } \\
\text { they will be granted entry to university courses. }\end{array}$ & 52 \\
\hline 2 & $\begin{array}{l}\text { Foundation mathematics for mature students pursuing an access } \\
\text { foundation year (in engineering) following which they will be granted } \\
\text { entry to university engineering courses. }\end{array}$ & 296 \\
\hline 3 & $\begin{array}{l}\text { First year engineering mathematics. Focus on algebra, complex } \\
\text { numbers, vectors, series, functions and differential calculus. }\end{array}$ & 287 \\
\hline 4 & $\begin{array}{l}\text { Second year engineering mathematics. Focus on linear algebra, } \\
\text { Laplace transforms and Fourier series. }\end{array}$ \\
\hline 5 & $\begin{array}{l}\text { Business mathematics. First mathematics module taken by } \\
\text { business students in their second year. Focus on algebra, matrices, } \\
\text { differential calculus, curve sketching and basic financial } \\
\text { mathematics. }\end{array}$ \\
\hline 6 & $\begin{array}{l}\text { Second year science statistics. Focus on fundamentals of } \\
\text { probability, most widely used statistical distributions, and statistical } \\
\text { inference. }\end{array}$ \\
\hline 7 & $\begin{array}{l}\text { First year technological mathematics for technology students. } \\
\text { Focus similar to module 3, however with a lower difficulty level. }\end{array}$ & 381 \\
\hline
\end{tabular}




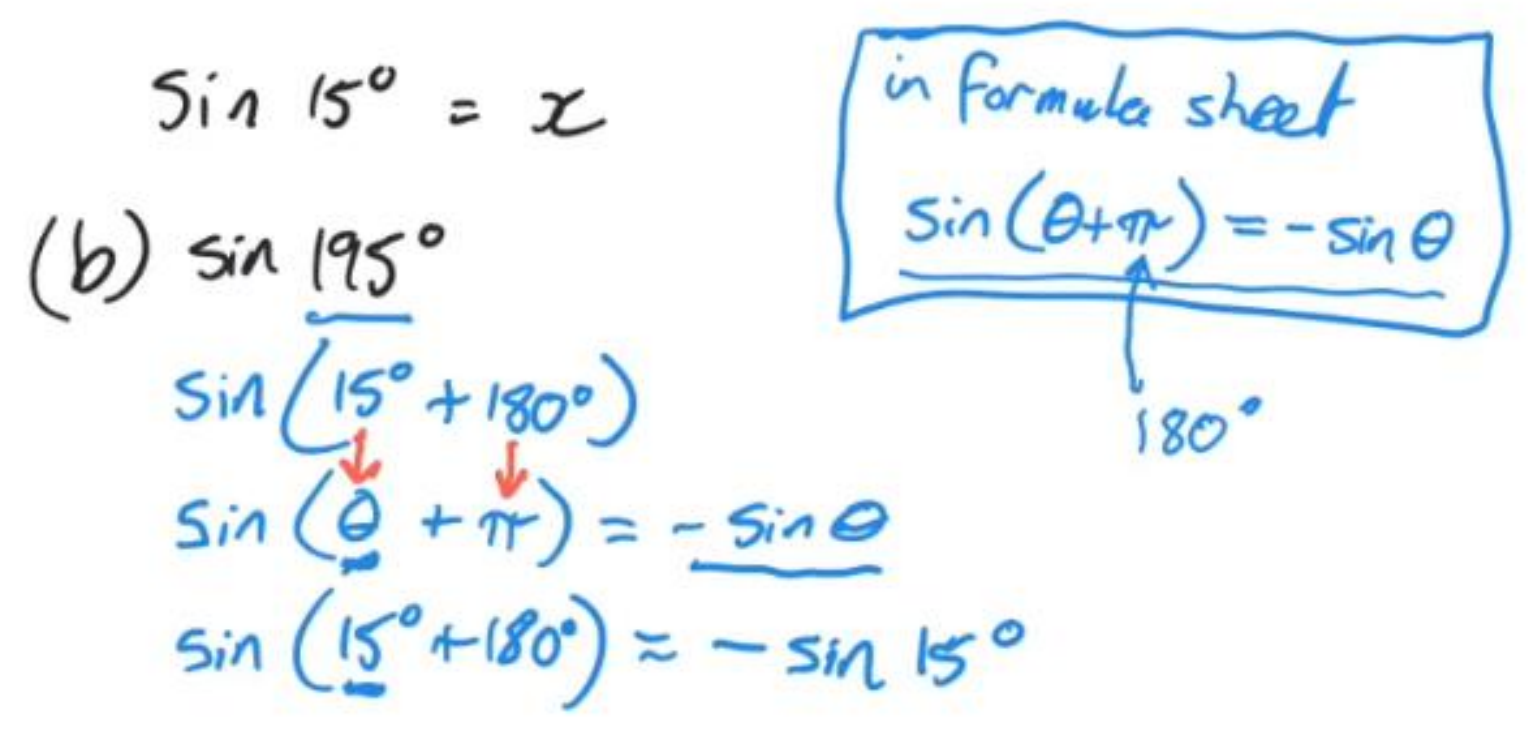

Figure 1. Screenshot from revision videos

Data was extracted from Sulis from the period $10^{\text {th }}$ September 2018 until $1^{\text {st }}$ November 2018, i.e. from the first day of the semester until the day of the midterm examination for the trial group in the eighth week of term. Data was extracted on the number of student members in each Sulis site, on which videos were viewed, and the number of times each video was viewed (the only option was to extract this data manually at certain times, there is no option on Sulis to inform the user of how many members a site had on a given day/time, the data available is restricted to the total number of members at the time of logging in). Data was also collected on students' usage of the MLC drop-in centre and support classes provided by the MLC.

\section{Results and Analysis}

The number of student members in each of the Sulis sites over time is given in figure 2 (the trial group received the email advertising the midterm revision videos on 16/10/18 during the sixth week of the 12 week academic term).

It is seen in figure 2 that the number of student members in the Sulis site for the trial group is approximately five times higher on $01 / 11 / 2018$ than it was on 15/10/2018. The number of student members in the other Sulis sites remained similar throughout this time. The number of videos viewed per module over time from data taken at the end of each work day is detailed in table 2.

The number of total video views for the trial group increased by 160 percent from the day prior to this group receiving the email advertising the midterm revision videos $(15 / 10 / 18)$ to the day after the trial group received this email $(17 / 10 / 18)$. During the period $19 / 10 / 18-01 / 11 / 18$, each time the data was collected there was an increase in the number of total video views by the trial group from the previous data collection time point. This increase ranged from a minimum of $14.5 \%$ to a maximum 


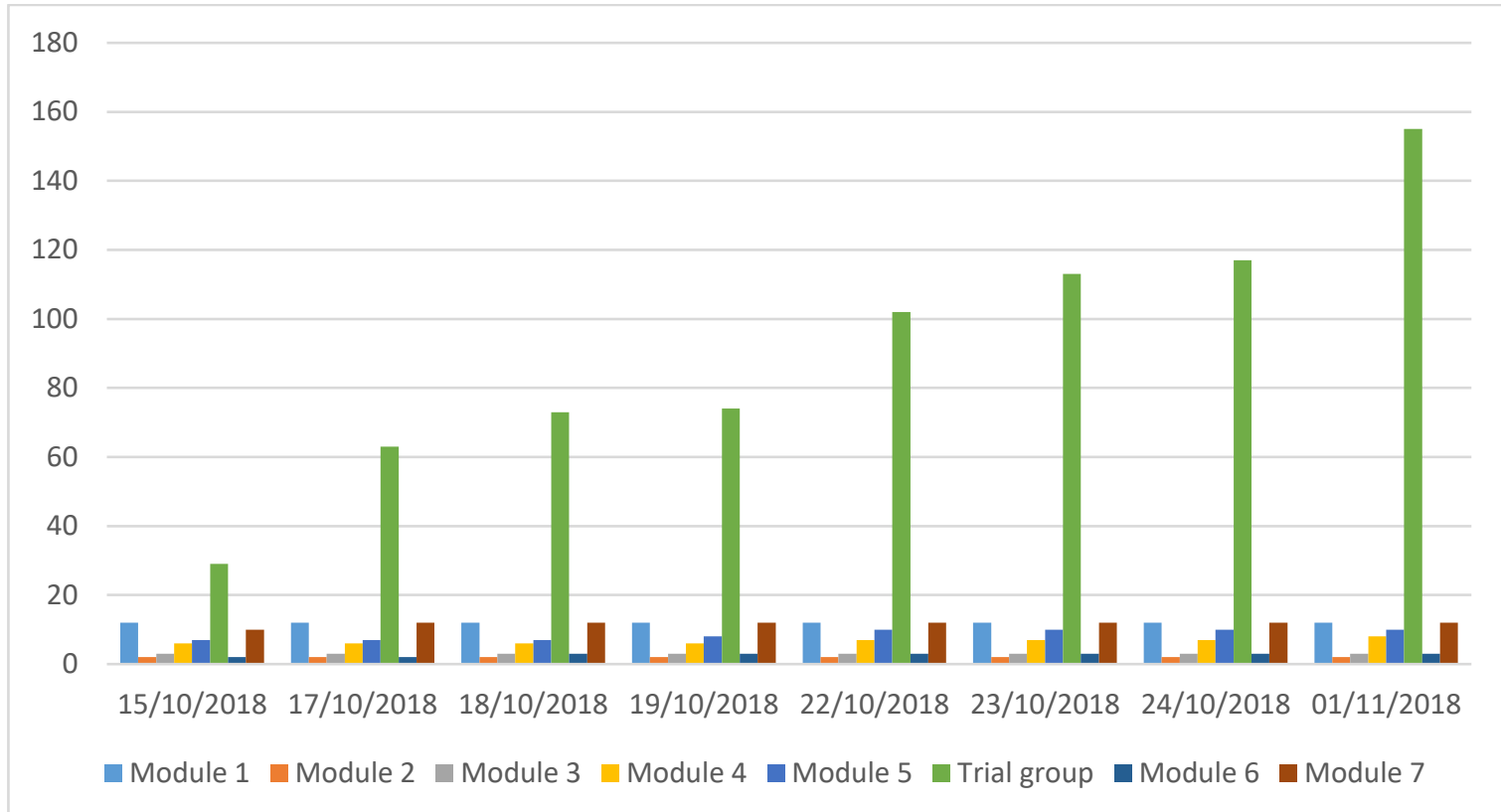

Figure 2. Number of student members in each Sulis site over time

Table 2. Number of total video views in each Sulis site over time

\begin{tabular}{|c|l|l|l|l|l|l|l|l|}
\hline & $\mathbf{1 5 / 1 0 / 1 8}$ & $\mathbf{1 7 / 1 0 / 1 8}$ & $\mathbf{1 9 / 1 0 / 1 8}$ & $\mathbf{2 2 / 1 0 / 1 8}$ & $\mathbf{2 4 / \mathbf { 1 0 } / \mathbf { 1 8 }}$ & $\mathbf{2 6 / 1 0 / 1 8}$ & $\mathbf{2 9 / 1 0 / 1 8}$ & $\mathbf{0 1 / 1 1 / 1 8}$ \\
\hline $\begin{array}{c}\text { Trial } \\
\text { group }\end{array}$ & 143 & 372 & 491 & 568 & 942 & 1079 & 1595 & 2597 \\
\hline $\begin{array}{c}\text { Module } \\
\mathbf{1}\end{array}$ & 158 & 158 & 159 & 165 & 165 & 165 & 165 & 203 \\
\hline $\begin{array}{c}\text { Module } \\
\mathbf{2}\end{array}$ & 0 & 0 & 0 & 0 & 0 & 0 & 0 & 0 \\
\hline $\begin{array}{c}\text { Module } \\
\mathbf{3}\end{array}$ & 0 & 0 & 0 & 0 & 0 & 0 & 0 & 0 \\
\hline $\begin{array}{c}\text { Module } \\
\mathbf{4}\end{array}$ & 5 & 5 & 5 & 5 & 5 & 5 & 5 & 5 \\
\hline $\begin{array}{c}\text { Module } \\
\mathbf{5}\end{array}$ & 57 & 57 & 75 & 76 & 76 & 76 & 76 & 76 \\
\hline $\begin{array}{c}\text { Module } \\
\mathbf{6}\end{array}$ & 3 & 3 & 3 & 3 & 3 & 3 & 3 & 4 \\
\hline $\begin{array}{c}\text { Module } \\
\mathbf{7}\end{array}$ & 142 & 188 & 188 & 188 & 188 & 188 & 188 & 188 \\
\hline
\end{tabular}


of $62.8 \%$. The highest increase in the number of total video views for the other modules was $32.4 \%$ for Module 7. However, this increase occurred at one time point only and the number of total video views for the module remained the same thereafter. There was little to no change in the number of total video views for the remaining modules over the time period 15/10/18 - 01/11/18.

The level of engagement with the online support was sustained by the trial group. The total videos views for each module at the end of the semester (after examinations) is shown in table 3 . Note that 45 extra views of the midterm revision videos were made after the examination, therefore 1,555 views of other videos were made between the end of the midterm examination and the end of the semester by the trial group.

Table 3. Total number of total video views in each Sulis site at the end of semester

\begin{tabular}{|l|l|l|l|l|l|l|l|l|}
\hline Module & $\begin{array}{l}\text { Trial } \\
\text { group }\end{array}$ & $\begin{array}{l}\text { Module } \\
\mathbf{1}\end{array}$ & $\begin{array}{l}\text { Module } \\
\mathbf{2}\end{array}$ & $\begin{array}{l}\text { Module } \\
\mathbf{3}\end{array}$ & $\begin{array}{l}\text { Module } \\
\mathbf{4}\end{array}$ & $\begin{array}{l}\text { Module } \\
\mathbf{5}\end{array}$ & $\begin{array}{l}\text { Module } \\
\mathbf{6}\end{array}$ & $\begin{array}{l}\text { Module } \\
\mathbf{7}\end{array}$ \\
\hline $\begin{array}{l}\text { Number } \\
\text { of views }\end{array}$ & 4197 & 247 & 0 & 0 & 124 & 787 & 13 & 562 \\
\hline
\end{tabular}

\subsection{Results on the trial group}

The number of views per video for the top 20 viewed videos is shown in figure 3 . Note that videos such as 1 (a) or 4(b) (i.e. number(letter) format) are from the midterm revision videos. All other videos are not specific to the students' past midterm examination.

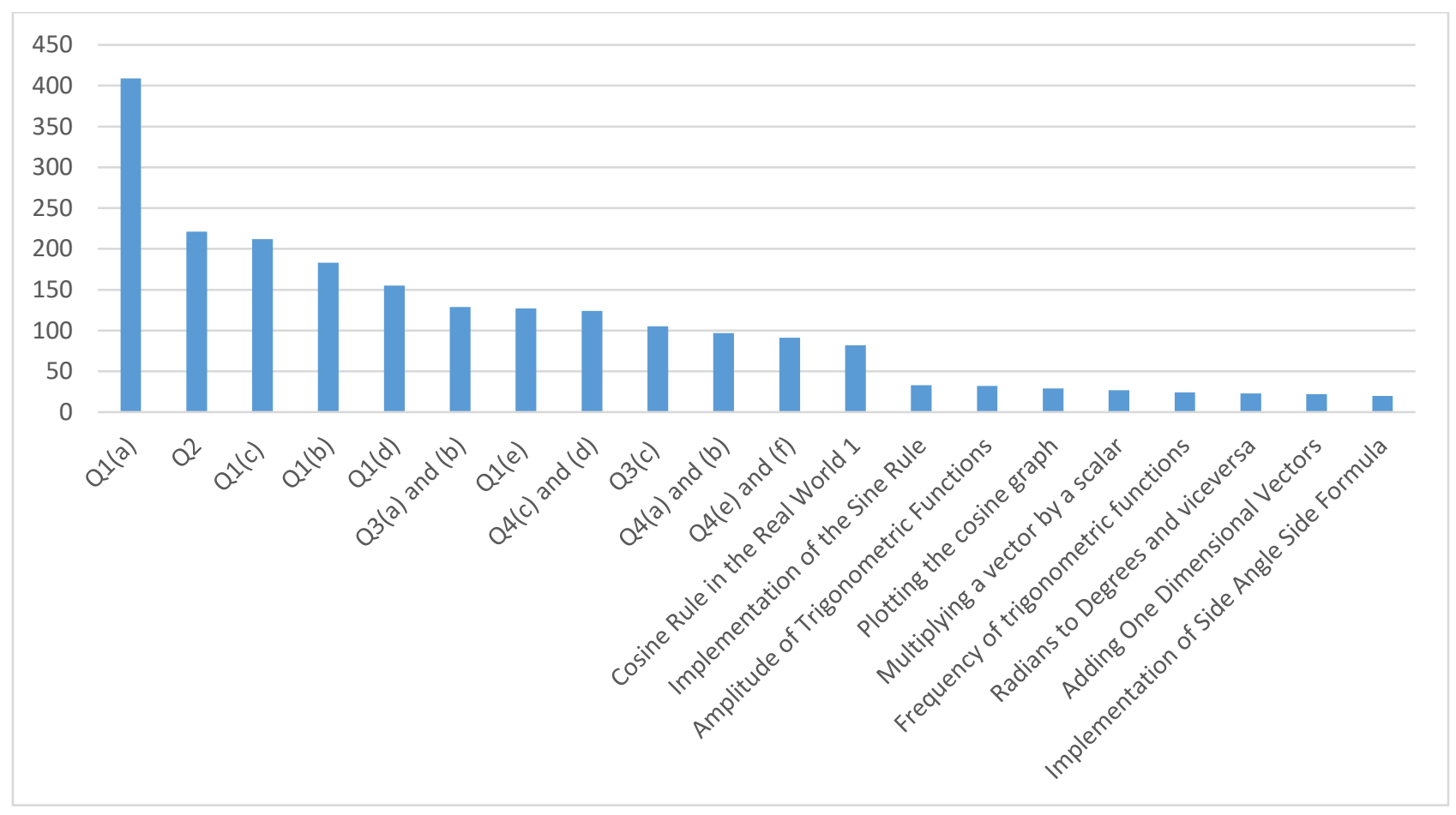

Figure 3. Top 20 videos viewed

As seen in figure 3, though the majority of videos viewed were from the students' past examination paper, 744 views of other videos (29\% of total video views) not specific to the midterm questions were made, which is much higher than any of the other modules. This suggests that the attractive 
element of the midterm videos being made available has also led to students viewing the MLC's other online support.

The attendance figures at the MLC drop-in centre and at the MLC's evening support classes (up until the end of the eighth week of term) for the trial group's module compared to previous years of students from the same module (where they did not have the online revision videos) are shown in figure 4. Figure 5 shows the attendance figures for weeks 3-5 of term and for weeks 6-8 of term (before and after the advertising of midterm revision videos respectively).

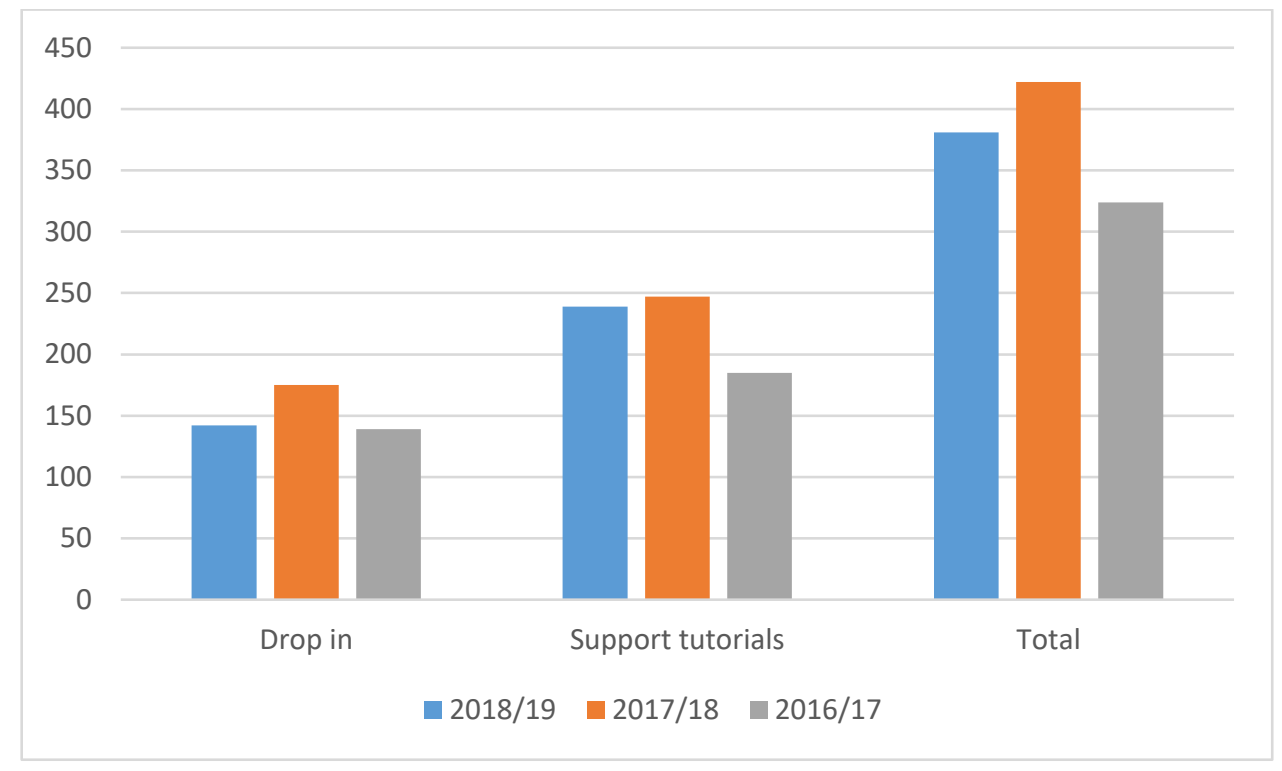

Figure 4. Total attendances made by students from the trial group (2018/19) and total attendances made by students from the same module for the previous two academic years.

The attendances at the MLC drop-in by students in the trial group (2018/19) were lower ( 20\%) than the attendances from students of the same module in $2017 / 18$ but on par with students in this module in 2016/17. The attendances at the MLC support tutorials by the students in the trial group (2018/19) was slightly lower $(\sim 4 \%)$ than the attendances from students of the same module in the previous academic year but higher ( 33\%) than students in this module in 2016/17.

In each of the three semesters, there was a decrease in the total attendances at the MLC drop-in made by students from this module from weeks $3-5$ to weeks $6-8$. This decrease $(\sim 52 \%)$ was approximately the same for each of the three years. There was a decrease of $13 \%$ and $29 \%$ in the total attendances at the MLC support tutorials made by students from this module from weeks 3-5 to weeks $6-8$ for the $2018 / 19$ and $2017 / 18$ academic years respectively. Although the new marketing strategy resulted in increased use of the MLC online support service by the trial group, it did not lead to a higher decrease in the number of physical attendances by the trial group at the MLC drop-in compared to the number of physical attendances by students from the same module in the previous two years. 


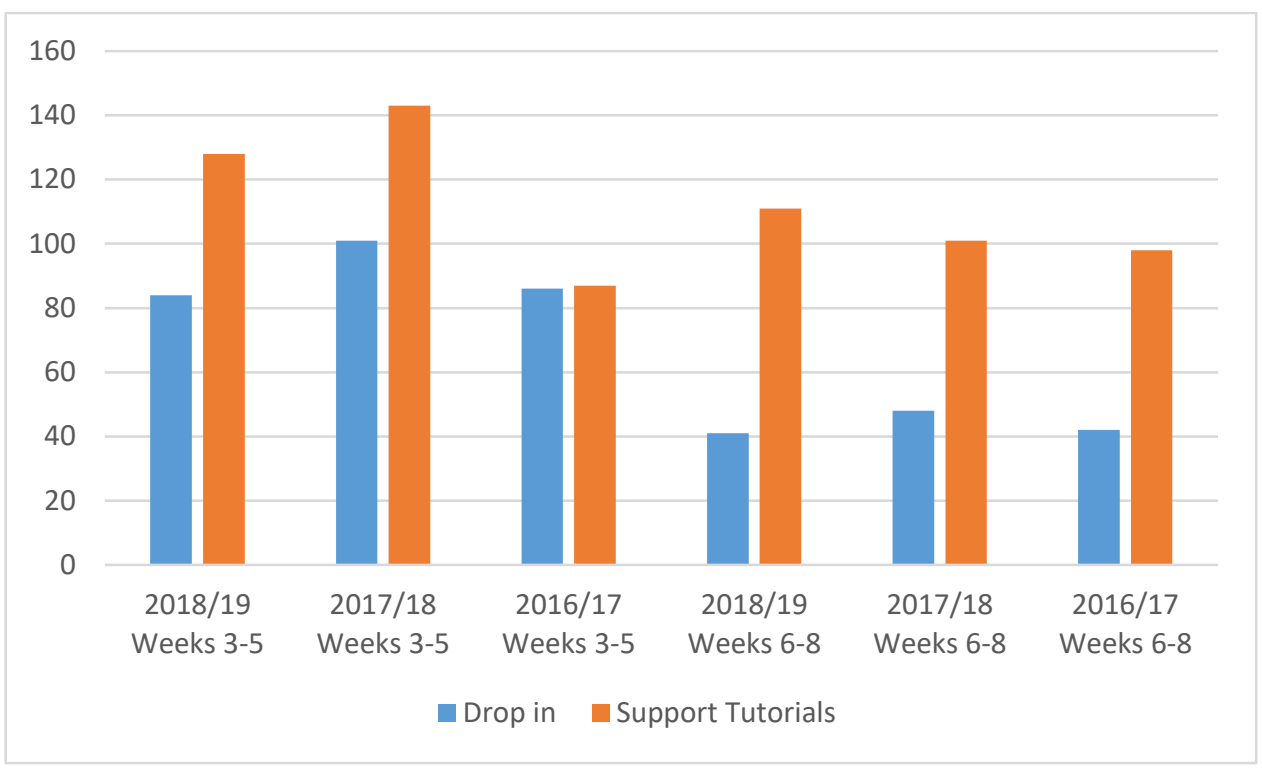

Figure 5. Total attendances made by students from the trial group (2018/19) in weeks 35 and weeks $6-8$ and total attendances made by students from the same module for the previous two academic years in weeks 3-5 and weeks 6-8.

\section{Conclusion}

Tailoring online mathematics support to the specific mathematics that students are studying is an effective strategy to get more students to engage in online mathematics support. The lower decrease in the total attendances at the MLC support tutorials in the 2018/19 academic year, in addition to the substantial increased use of online support is suggestive of students availing themselves of an appropriate level of mathematics support. The familiarity of the online midterm videos as a hook to increase engagement with online support led to increased engagement with online support, which was not solely restricted to the midterm videos and this increase was sustained over time.

\section{References}

Jacob, M. and Ní Fhloinn, E., 2018. A quantitative, longitudinal analysis of the impact of mathematics support in an Irish university. Teaching Mathematics and its Applications, accepted. https://doi.org/10.1093/teamat/hry012

Ní Shé, C., Mac an Bhaird, C., Ní Fhloinn, E. and O'Shea, A., 2017. Students' and lecturers' views on mathematics resources, Teaching Mathematics and its Applications, 36(4), 183-199. https://doi.org/10.1093/teamat/hrw026

Sappleton, N., \& Lourenço, F., 2016. Email subject lines and response rates to invitations to participate in a web survey and a face-to-face interview: the sound of silence. International Journal of Social Research Methodology, 19(5), 611-622. https://doi.org/10.1080/13645579.2015.1078596

Symonds, R., Lawson, D., Robinson, C., 2008. Promoting student engagement with mathematics support. Teaching Mathematics and its Applications, 27(3),140-149.

https://doi.org/10.1093/teamat/hrn011 